\title{
THE ESPOSITO ERISOPHAKE AND CATARACT EXTRACTION*
}

\author{
BY
}

\author{
ALBERT C. ESPOSITO \\ Huntington, West Virginia, U.S.A.
}

IN 1953 I described an erisophake (Esposito, 1953), which I had devised in 1950 , and which $I$ had been, and have been, using since that time in cataract surgery. Since the original article appeared, this instrument has been used successfully and extensively by many ophthalmologists as noted by many writers, including Hope-Robertson (1954) and Givnor (1953). Of interest has been the attempted modification of this erisophake by other surgeons. This modification has been found to fail in one important respect: the Esposito erisophake develops just enough negative pressure to hold the capsule of the cataractous lens securely for the extraction, but cannot develop an excessive negative pressure as do some of the other instruments. Excessive pressure often breaks the capsule and even aspirates vitreous, and this may deter the operator from the use of the erisophake in cataract extractions.

In the present series of over 600 cataract extractions, this erisophake (Figure) remains for me, as for many surgeons, the instrument of choice, and an attempt has been made to simplify the intracapsular round-pupil cataract extraction procedure, especially for the lone operator.

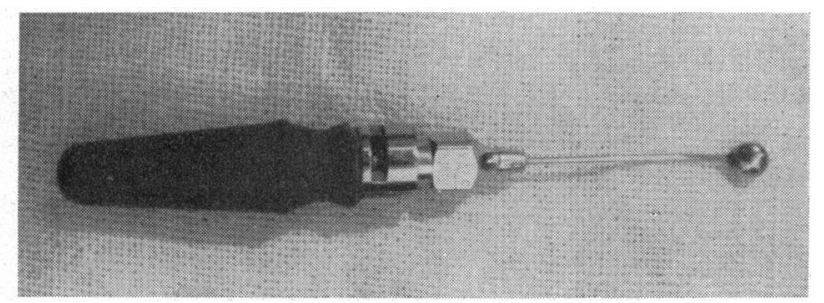

FIGURE.-Erisophake used in the present series of 600 cases.

A careful pre-operative ocular examination with slit lamp and tonometer helps in planning the operative routine, and, at the time of operation, massage helps to soften the globe. Careful laboratory studies, physical examination, and the use of Thorazine, Demerol, Diamox, and a pentobarbital in appropriate dosages just before the operation have also contributed to this success. 
For local anaesthesia and mydriasis, Pantocaine 1 per cent., Neo-synephrine 10 per cent. solution, and atropine sulphate 1 per cent. solution, are used. The combination of Neo-synephrine and atropine appears to keep the pupil dilated after the anterior chamber is opened.

At operation, the lashes are cut routinely as a safeguard against implantation cysts (Esposito, 1956). Hyaluronidase with 2 per cent. Novocaine by the van Lint or O'Brien technique is used for akinesia. For the retrobulbar injection, $1.5 \mathrm{ml}$. of solution with the shorter $3.5 \mathrm{~cm}$. 23-gauge needle are used to eliminate the possibility of retrobulbar haemorrhage. According to Atkinson's method firm pressure is applied to the globe for 3 to 5 minutes (Atkinson, 1956). I am convinced that this manoeuvre is largely responsible for preventing vitreous loss.

If the palpebral aperture is small and a canthotomy is found to be necessary, a haemostat applied to the area to be incised to crush the tissues before incision will reduce the bleeding.

Routine lid sutures are advocated even though a speculum is used. They are of value in a threatened or actual loss of vitreous and prevent pressure on the globe.

A routine bridle suture, another safeguard, is used with 6-0 Ethicon Nylon suture, product B-660, with an atrolic needle (Esposito, 1955). This suture is light blue in colour and is therefore readily visible on the sterile drapes. I found that, occasionally, it was difficult to remove the usual black silk sutures from the bridle suture area, even a gentle attempt resulting in the collapse of the air bubble in the anterior chamber. This smooth nylon suture is easily inserted with the cutting needle and easily removed. A small serrefine is used to hold the suture taut.

In the controversy of the limbal versus the fornix-based flap, every surgeon has his own opinion. The procedure which the operator finds easiest to perform should be used: I prefer the fornix-based flap of van Lint, Kuhnt, and Post. I find it quick to perform, and it appears to have the advantage of permitting plasma from the conjunctival surface to ooze into the corneal incision and to speed healing.

Multiple corneo-scleral sutures, either pre- or post-placed and of either $6 / 0$ black silk or catgut, are recommended. Swan has informed me that, in one of every four cases in which catgut was used, a fistulizing bleb developed at the site. In this series I have used five or more $6 / 0$ black silk corneal scleral sutures. The McLean (1940) corneo-scleral suture, or a modification thereof, appears to be the favourite. I use two pre-placed McLean sutures at 11 and 2 o'clock, and then three or more post-placed sutures at 10, 12, and 1 o'clock. I have found the Burch pick invaluable in positioning the pre-placed suture and I use the Paufique and Barraquer corneal forceps for holding the corneal and scleral margins for the post-placed sutures. I use the Barraquer cilia forceps for tying all sutures, and the Castroviejo needleholder for suturing. Multiple corneo-scleral sutures permit tight closure of 
the wound, and so reduce the incidence of iris prolapse, the occurrence of which is now extremely rare, and this makes early ambulation possible.

As for the actual cataract incision, the keratome versus scissors controversy continues, most surgeons conceding that both methods are useful (Davis, 1954). The surgeon's choice is based on the ease and dexterity with which he accomplishes the section. I use the von Graefe knife and the Castroviejo or Barraquer angular scissors, and I attempt to bevel the section for better approximation of the edges (Dunnington, 1956).

The question of limbal versus scleral section should be settled on the basis of the pre-operative slit-lamp appearance of the cornea. If no contraindications are present, a limbal type of corneal side section is routinely performed. This may account for the fact that there were only two cases of post-operative hyphaema in 600 cases. The section should be adequate and should open to at least 50 per cent. of the circumference of the cornea, adequate exposure being as necessary in ocular as in general surgery. If an erisophake is to be used to extract the cataract, enlargement of the section from 1 to $2 \mathrm{~mm}$. on the temporal side can be helpful in tumbling the lens (Clark, 1954) and preventing trauma to the posterior surface of the cornea and Descemet's membrane, besides reducing the risk of striate keratitis, a complication which is also becoming a rarity.

Peripheral iridotomy or iridectomy versus complete iridectomy is another problem. In this series of 600 cases I routinely attempted to perform a roundpupil extraction using one or two peripheral iridotomies or a small peripheral iridectomy. The round pupil does assist in holding back the face of the vitreous, as has been noted by Davis (1954) and others.

The enzyme alpha-chymotrypsin has been used in selected cases during the past 18 months, in those patients who had shown no signs of liquid vitreous, or whose fellow eye showed none. Either the $1: 5,000$ or the $1: 10,000$ strength was used. The time interval was shorter with the stronger solution. I have not yet used it for patients below 20 or above 60 years of age. I have used both the Spanish and the United States preparations, and the results are comparable. I use the erisophake or the erisophake bulb with a Randolph cannula at the tip to irrigate the enzyme into the posterior chamber, and then wait 2 to 4 minutes and irrigate the anterior chamber with saline, before attempting extraction with the erisophake. Pearlman (1956), reviewing 1,337 cases of senile cataract extraction, noted that "the use of the erisophake as compared to the lens forceps produces a lower rate of capsule rupture and less lens residue when the capsule was inadvertently ruptured". The Bell, Dimitry, and other erisophakes all have their adherents, but the Esposito erisophake, because of its length, weight, adequate negative pressure, and similarity in size and weight to other ocular instruments, is easier to use.

In all cases an attempt was made to tumble the lens; however, when the enzyme is added, either the sliding or the tumbling technique can be used, depending on the depth of the anterior chamber. 
When the sutures have been tied, I routinely inject air into the anterior chamber to push back the face of the vitreous, keep the iris in its proper position, and permit the chamber angle to remain wide open, thus preventing the formation of synechiae in the chamber angle.

\section{Summary}

The use of the Esposito erisophake is described to assist the lone ophthalmic surgeon to improve his technique, and advice is given on operative complications.

\section{REFERENCES}

Atkinson, W. S. (1956). Trans. Amer. Acad. Ophthal. Otolaryng., 60, 376.

Clark, W. B. (1954). Ibid., 58, 378.

DAVIS, F. A. (1954). Ibid., 58, 334.

DunNington, J. H. (1956). A.M.A. Arch. Ophthal., 56, 639.

Esposito, A. C. (1953). Brit. J. Ophthal., 37, 61. (1955). Amer. J. Ophthal., 40, 251. (1956). Ibid., 41, 115.

GIVNoR, (1953). Personal communication.

HOPE-ROBERTSON, W. J. (1954). Trans. ophthal. Soc. N.Z., p. 12.

McLean, J. M. (1940). Arch. Ophthal. (Chicago), 23, 554.

Pearlman, M. D. (1956). Eye, Ear, Nose, Thr. Mthly, 35, 43. 